\title{
¿Mantener las murallas o demolerlas? Urbanismo y disputas sociales en Cartagena, Colombia y San Juan, Puerto Rico (1880-1920)
}

Narcís Bassols. Universidad Externado de Colombia, Bogotá, Colombia; Universitat Rovira i Virgili, Tarragona, España.

Carlos-E. Soutto-Colón. Envision Puerto Rico L3C, San Juan, Puerto Rico.

RESUMEN | Este artículo es resultado de la investigación de dos 'anomalías de planeación urbana' en América Latina: el mantenimiento de las murallas urbanas de Cartagena de Indias, Colombia y de San Juan de Puerto Rico. Aunque ambos sistemas defensivos son hoy en día joyas turísticas, tras su preservación hay una larga historia de controversias. Al examinar ambos casos, el presente artículo considera cuestiones de planeación urbana pero también socioeconómicas, lo que convierte estos dos ejemplos en únicos, puesto que la norma en el continente fue derribar las murallas. En el caso sanjuanero, un uso militar continuado; y en Cartagena, una desidia a la hora de derribar y una turistificación temprana explican el mantenimiento de las murallas. De todas formas, el artículo subraya que su preservación no produjo grandes diferencias entre ambas ciudades ni tampoco en sus centros históricos, si se las compara con otras ciudades similares de la región.

PALABRAS CLAVE | historia urbana, patrimonio, política urbana.

ABSTRACT | This article is the result of research on two 'planning anomalies' in Latin America: The preservation of the city walls of Cartagena de Indias, Colombia and San Juan, Puerto Rico. Although both defensive systems are tourist icons nowadays, behind their retention lays a long history of contestation. Planning, spatial and socio-economic issues are considered in the article, which deems these processes unique and idiosyncratic, for the norm throughout the continent was to tear down walls of this type. In San Juan, a long period of military use and in Cartagena a comfortable attitude as well as an early touristification process ultimately explain the preservation of the walls. However, keeping the walls has not led to a significant difference for urban planning processes in the two cities, nor in the two cities centers, when compared to other similar cites of the region.

KEYWORDS | urban history, heritage, urban politics. 


\section{Introducción, contexto y metodología}

La presente investigación indaga por qué se dejaron en pie las murallas urbanas de Cartagena de Indias, Colombia, y de San Juan de Puerto Rico, considerando dos contextos: el histórico y el urbano. Mientras en prácticamente la totalidad de las ciudades latinoamericanas, desde Santo Domingo hasta Montevideo, fueron destruidas las murallas defensivas coloniales que rodeaban sus centros históricos, los sistemas de murallas de Cartagena y San Juan sobrevivieron en gran parte. Observando el trazado urbano actual de estas dos ciudades, es posible preguntarse por qué se mantuvieron tales estructuras, ya que eran consideradas obsoletas y fueron un claro estorbo al desarrollo urbano de principios del pasado siglo. La cuestión cobra mayor relevancia si se considera que sus centros históricos poseen hoy en día un valor indiscutible: los dos figuran en la lista de patrimonio mundial de la Unesco desde principios de la década de 1980, lo cual ha significado que ambas ciudades se han promovido como 'destinos turísticos patrimoniales', de modo que hoy en día se hallan entre los más buscados del Caribe. Las murallas las distinguen y hacen únicas, ya que ninguna otra en América Latina y el Caribe ha conservado estas estructuras, unos 3,5 km en el caso de Cartagena y 2,3 km en San Juan. Hoy en día se pueden admirar castillos y fortalezas en otras ciudades de la región, como La Habana, Santo Domingo, Ciudad de Panamá, Bermuda o Cumaná, pero en ellas ya no hay murallas que mostrar, o bien poseen solamente los restos de ellas. Algún caso excepcional, como el de Campeche, México, ha experimentado el ciclo completo de construcción-destrucción-reconstrucción de sus murallas urbanas: allí se empezó a reconstruir los muros hace ya algunas décadas y recientemente se ha continuado restableciéndolos con el objeto de atraer más turistas.

La metodología usada para el presente artículo es descriptivo-comparativa y, por tanto, de carácter selectivo (Oxman \& Guyatt, 1993). De acuerdo con Bernal (2010), Cortés e Iglesias (2004) y Hernández, Fernández \& Baptista (2010), este tipo de aproximación, al centrarse en la narración detallada de una problemática, permite identificar rasgos, características e información alusiva al objeto estudiado, abordando sus implicaciones y tendencias. Tal proceder se acerca al método del estudio de caso (Hamel, Dufour \& Fortin, 1993; Stake, 1995), el cual reivindica el conocimiento de la realidad a través del examen de fenómenos concretos y abordables.

En concordancia con los postulados del párrafo anterior, el trabajo de campo en el que se basa el presente artículo ha sido de carácter eminentemente cualitativo, con la investigación de fuentes primarias (archivos de prensa, planos históricos y actuales de Cartagena y San Juan) que dieron los datos base, así como literatura secundaria (libros y artículos de historia de la época y literatura sobre historia de la planeación urbana de ambas ciudades y en América Latina en general; cf. listado de referencias al final del artículo), de la que resultó el marco histórico-social en el que se inscribe la presente investigación. Los resultados obtenidos se ratificaron mediante algunas entrevistas informales con expertos urbanistas e historiadores de ambas ciudades (tres en Cartagena y dos en San Juan). Se hizo especial esfuerzo en ilustrar los acontecimientos y devenires sociales respecto al urbanismo de la 
época, a la vez que en comparar ambos casos. No se deben esperar generalizaciones a partir de las dos ciudades estudiadas, por la especificidad de ambas; sin embargo, sí creemos que esta misma excepcionalidad puede ofrecer visiones interesantes sobre los procesos urbanos de otras ciudades latinoamericanas de finales del siglo xIX y primeras décadas del $\mathrm{xx}$, en especial el encaje urbano de las áreas históricas en el resto de la ciudad, con el trasfondo de las situaciones sociopolíticas respectivas.

Los hechos que se describen abarcan aproximadamente de 1880 a 1920 y deben ser puestos en la perspectiva general de las ciudades latinoamericanas y caribeñas, en su proceso de reformarse y conformarse a estándares urbanos europeos primero, y norteamericanos después. Es decir, el período estudiado en el cual suceden las 'anomalías' de mantener las murallas en Cartagena y San Juan es enmarcado en la fuerte influencia ejercida por el urbanismo de Europa y Norteamérica, sobre lo cual diserta Hardoy (1992, p. 20-21), cuando dice específicamente que "the first building and environmental ordinances and the beginning of municipal regulation [in Latin America, n. del a.] were an attempt to respond to ideas on public health that had developed in Europe". Al otro lado de este marco temporal no hallamos ya la "higiene" como impulsora de reformas urbanas, sino la "modernidad". Esta deviene un concepto básico según Montoya Garay (2013), que en su historia de la planeación urbana de Bogotá señala: "La modernización se convirtió en la excusa favorita a la hora de legitimar las políticas urbanas en la mayor parte del siglo xx" (p. 76). La situación especial a la que entró Puerto Rico tras devenir territorio estadounidense en 1898 implicó la preferencia por la 'gran' arquitectura como medio rápido para crear una nueva identidad en la isla, según señala Pabón-Chameco (2016, p. 13 y ss.).

La importancia histórica y simbólica de ambas ciudades es innegable: ambas fueron fundadas en lugares de alto valor geoestratégico. San Juan era una isla con pronunciados acantilados a un lado, y Cartagena, un grupo de islas con ciénagas que las conectaban (figuras 1 y 2). Puerto Rico era la posesión española más oriental en las Américas, lo cual la convirtió en punto obligado de conexión marítima con España. Cartagena era la puerta a las regiones andinas de Suramérica y también guardiana del istmo centroamericano. Enormemente codiciadas por piratas y corsarios pagados por las potencias rivales de Castilla, ambas ciudades se fortificaron pronto para ser convertidas en plazas inexpugnables gracias a sus murallas, castillos y fuertes (posiblemente fueran, junto con La Habana, las urbes mejor defendidas del Nuevo Mundo). El proceso de construcción de las fortificaciones duraría siglos y marcaría no solo la forma de estas ciudades, sino también su estructura social y económica. Ambos puertos entraron a formar parte de la red portuaria establecida por los españoles en las costas del Caribe y Suramérica, cuyo fin era salvaguardar los intercambios entre la metrópoli y las colonias, una red que se mantuvo durante casi tres siglos.

El contexto de urbanismo desde 1880 hasta 1920 es un factor importante a tener en cuenta. En efecto, no pocos autores postulan que la planeación urbana empezó en América Latina en los años de 1920, con bastante retraso respecto a Europa (Almandoz, 2002, 2010; Hardoy, 1992). Este retraso es todavía más patente en Colombia, donde los estudiosos sitúan el inicio de la planeación urbana 'seria' hacia la década de 1930 (Montoya, 2013, p. 87). En Puerto Rico también se inicia la 
planeación urbana en esa década, lo cual resultó en la construcción de proyectos de vivienda subsidiados por el gobierno federal estadounidense; por su parte, en 1941 inició sus actividades el Puerto Rico Planning Board (Mignucci, 2012). Por tanto, los fenómenos descritos en este artículo se dan en una época anterior a la planeación urbana sistemática tal y como se entendió en el continente a partir de la década de 1930

Por otro lado, cabe subrayar que el mantenimiento de las murallas es algo inaudito, ya que en aquellas décadas no eran consideradas patrimonio cultural: la valoración social de las murallas se inicia en la década de 1910 en Cartagena de Indias (Giaimo, 2008, p. 8) y en el caso de Puerto Rico algunos autores ven un comienzo más tardío de este proceso, en la década de 1930 (Delgado Mercado, 2010, p. 63).

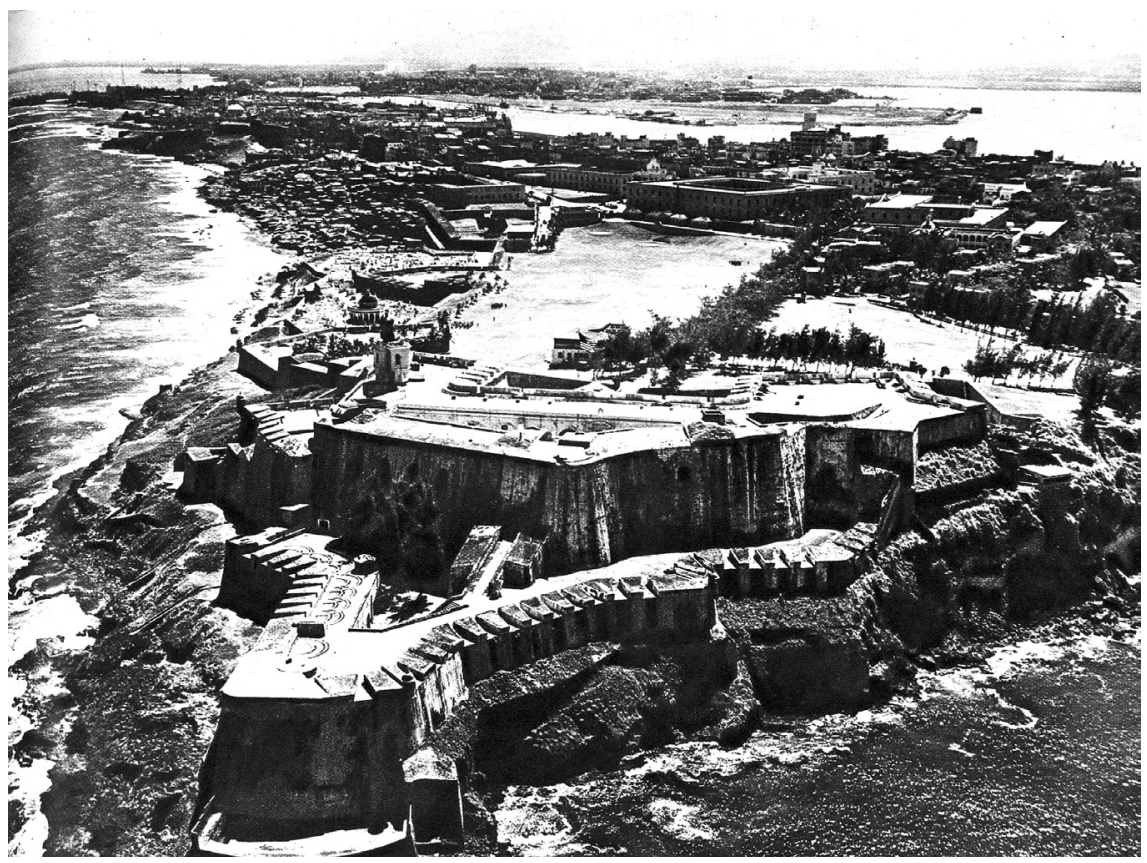

Figura I | Vista aérea de San Juan del año 1953 con el fortín de El Morro y el Viejo San Juan en primer plano. Se distingue claramente la ciudad antigua, que ocupa una isleta conectada a tierra. En el fondo, algunos de los nuevos barrios que se desarrollaron durante el siglo xx.

FUENTE: REVISTA MUNDO HISPÁNICO (I953, 67) 


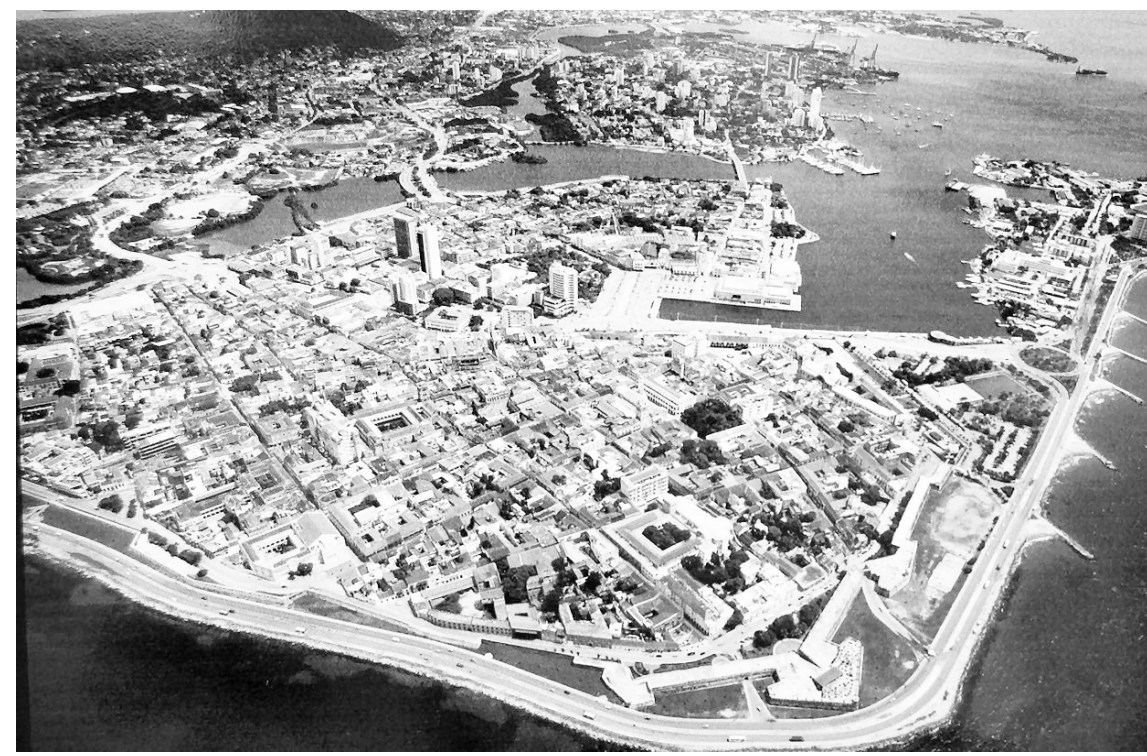

FIgURA 2 | Vista aérea general del centro histórico de Cartagena de Indias

(c. 2010). Se aprecia cómo la ciudad se acienta en un grupo de isletas conectadas por ciénagas y caños. En la parte inferior se ve claramente el baluarte de Santo Domingo y en la parte superior central se observa la isla de Manga.

FUENTE: FOTOGRAFÍA DE JAIME BORDA

\section{'Modernizando' las ciudades latinoamericanas: planeando nuevos espacios y demoliendo murallas}

A partir de la década de 1880, las economías latinoamericanas quedaron conectadas a Europa, y posteriormente a Estados Unidos, en calidad de proveedoras de materias primas (Hardoy, 1978, p. 106). Este cambio económico pronto tuvo consecuencias sociales y espaciales en las ciudades. En paralelo a este cambio, y a lo largo del siglo XIX, se fue dando un proceso de obsolescencia de las estructuras defensivas urbanas de Europa y América Latina, y a partir de las primeras décadas del xix, tras las independencias, en muchos países latinoamericanos se derribaron las murallas de las ciudades. Más tarde, ya en la década de 1860, estos procesos de demolición se relacionarían con las grandes reformas urbanas europeas, como la Ringstrasse en Viena o los bulevares de París, reformas que favorecieron la creación de avenidas anchas y espacios abiertos en la ciudad, muy en contraste con el laberinto de callejuelas que presentaban los centros históricos amurallados. Según seńala Almandoz (2002, p. 15), las metrópolis latinoamericanas, ya conectadas económicamente a la naciente economía global, intentarían pronto imitar las nuevas formas urbanas. Este autor establece un claro paralelismo entre cambios físicos y culturales, también en el caso latinoamericano, cuando escribe que "One of the key issues of the modernization of Latin America has to do with the importation of urban planning and design ideas 
from Europe, and the distinct way in which these were incorporated into the capitals of the emergent republics" (p. 4).

El discurso público sobre la 'modernización', una de cuyas demandas sine qua non parece ser la demolición de las murallas urbanas, llegó a Cartagena hacia finales del siglo xix. Samudio Trallero (2006) escribe lo siguiente a propósito de este proceso:

Unos pocos cartageneros (...) alzaron sus voces de protesta cuando fue derribado un sector de sus murallas en las primeras décadas del siglo xx, dizque para mejorar el saneamiento de la urbe como puerto de escala de los barcos que cruzarían el Canal de Panamá y porque se consideraba la muralla como un obstáculo para el progreso de la ciudad. (p. 3)

De hecho, entre las elites urbanas cartageneras existieron dos visiones completamente opuestas en lo que se refiere a las murallas: la de aquellos que las creían un estorbo al progreso y la de quienes las consideraban un patrimonio digno de ser preservado. Algunos autores ven en este último grupo a la elite más conservadora, directa descendiente de españoles, que deseaba mantener un fuerte símbolo visual de conexión con la antigua metrópoli. En cambio, el primer grupo estaría formado por la burguesía criolla emergente, que deseaba una clara ruptura con Espańa y presionó para que desaparecieran las murallas, en tanto símbolo claro de la época colonial (Ávila Domínguez, 2008, p. 66).

La alternativa entre mantenimiento y demolición fue discutida amplia y apasionadamente durante casi medio siglo en Cartagena, en un periodo que empezó con una apertura practicada en la Plaza de la Aduana en 1880 y acabó en 1924 con la demolición completa de una cortina de murallas, incluyendo tres bastiones. Asimismo, las políticas públicas urbanas respecto del tema fueron extraordinariamente dispares y se contradijeron no pocas veces. Así, en 1911, mientras los militares estacionados en la ciudad derruyeron un segmento de murallas, el entonces presidente Carlos E. Restrepo envió desde Bogotá un telegrama en que ordenaba detener este derribo (Programa de Naciones Unidas para el Desarrollo [PNUD]/Unesco, 1990, p. 17), un caso de especial interés, ya que es la primera orden del gobierno de la Nación tendiente a la conservación del patrimonio construido. La tensión causada por este dilema de planeación urbana fue particularmente alta desde los ańos 1911 hasta 1924: Carrillo, Cabarcas, Vargas y Puello (2013, p. 194) constatan que las discusiones públicas respecto al tema fueron "muy acaloradas".

En los años de la Primera Guerra Mundial continuaron los movimientos opuestos. Mientras la prensa local (y las elites criollas tras ella) seguía pidiendo la demolición, un curioso efecto de la guerra europea fue que la destrucción que generó acabó resultando en una mayor apreciación de "lo antiguo" en general, y del patrimonio militar construido en particular (Giaimo, 2002, p. 8; véase también figuras 3 А у 3 В). 

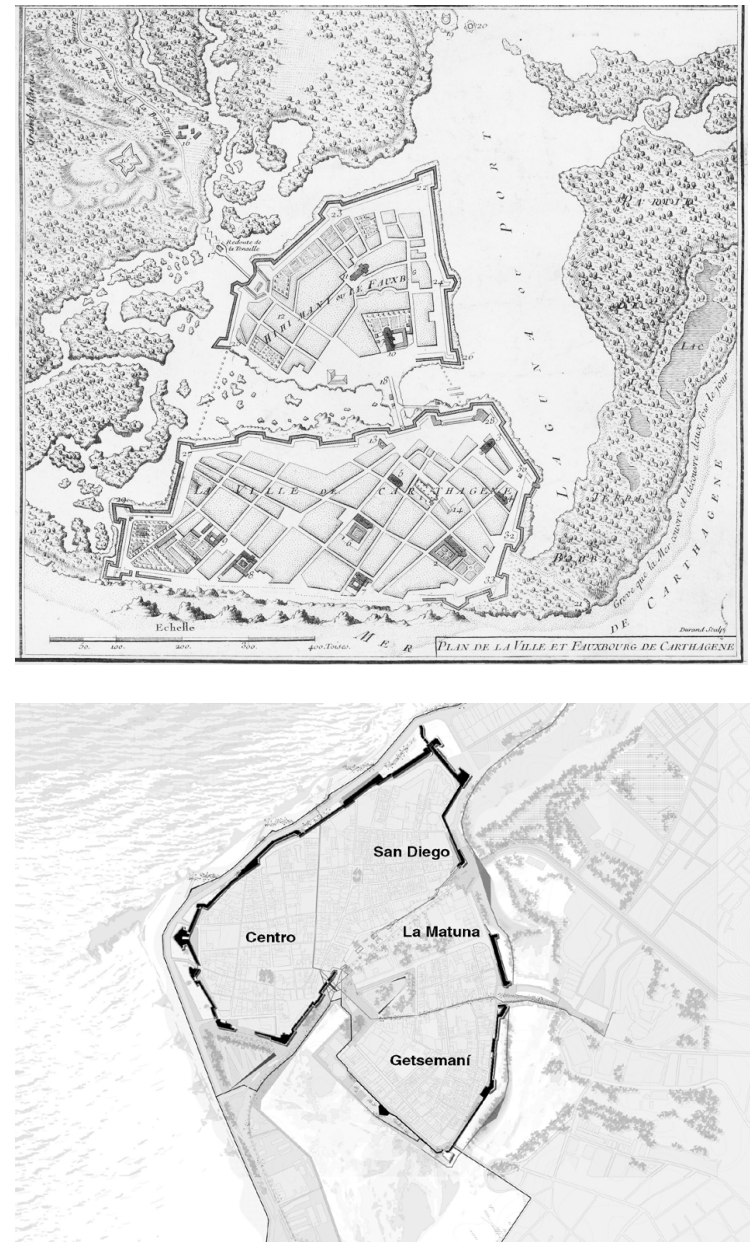

Figura 3A | Mapa de Cartagena de 1741. El centro urbano está en la base de la foto y el arrabal de Getsemaní en el centro; este último aparece solo parcialmente amurallado. FUENTE: MAPA FRANCÉS ELABORADO POR EL CARTÓGRAFO REAL JEAN DE BEAURAIN

FIGURA 3 B | Mapa actual del Centro Histórico de Cartagena con los cuatro distritos que lo conforman. Se presentan en líneas gruesas los segmentos de muralla que están en pie. FUENTE: ELABORACIÓN PROPIA CON BASE EN EN MAPA DE DOMINIO PÚBLICO OBTENIDO DE OPENSTREETMAP.ORG

San Juan vivió un proceso muy diferente: varios autores afirman que hacia mediados del siglo xix la ciudad se estaba sobrepoblando, siendo además un lugar muy insalubre. En este contexto, la sociedad puertorriqueña pidió al gobierno español autorización para derribar las murallas en 1865, de modo similar a los casos de La Habana y Barcelona (Flores, 2009; González Vales, 2009; Sepúlveda Rivera, 2000 , p. 70). Sin embargo, por motivos estratégicos, los militares estacionados en la isla bloquearon con todas sus fuerzas cualquier intento de derribo. Solo en $1897 \mathrm{el}$ gobierno de Madrid autorizó finalmente la demolición.

El entusiasmo popular que causó esta decisión, así como el alegre inicio de los trabajos de demolición, están reportados fielmente por la prensa de la época. Muchos hombres jóvenes accedieron a ayudar en la demolición, y el primer día de trabajos fue declarado festivo por las autoridades locales, que inauguraron solemnemente las obras. Sin embargo, la demolición fue muy limitada, ya que los trabajos (ejecutados mayormente de modo manual) progresaron muy lentamente y en 1898 estalló la 
guerra entre Estados Unidos y España, con lo cual solo una parte relativamente pequeña de la muralla fue derribada; concretamente, la que se hallaba alrededor de la zona de Puerta de Tierra (figuras 4A y 4B).

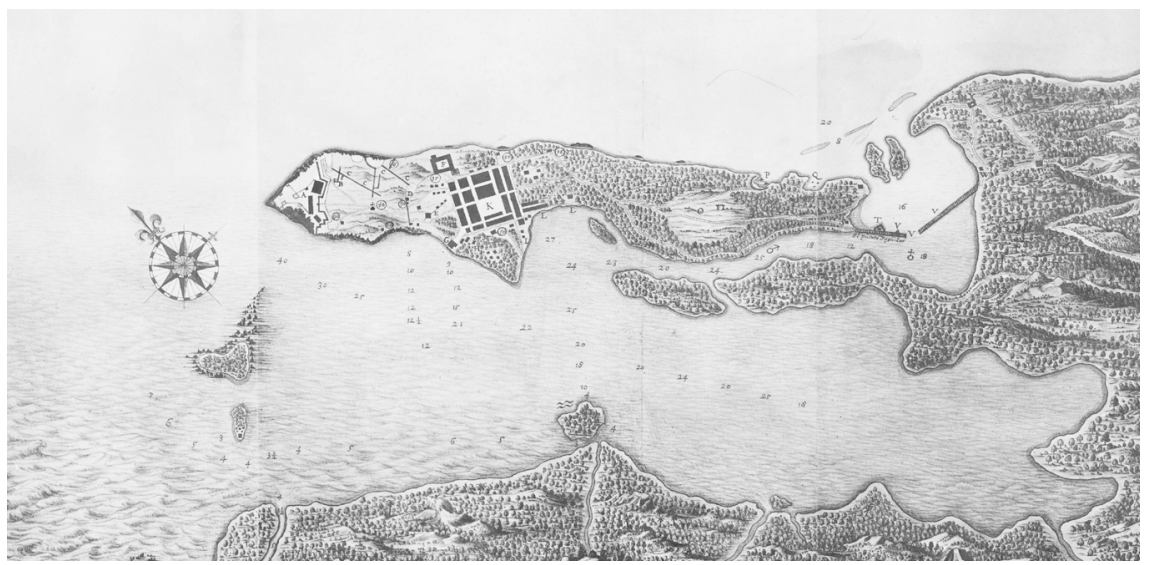

FIgURA 4A | Mapa de San Juan y sus alrededores del siglo Xvir. Los bloques en damero representan la naciente ciudad y el perímetro negro son las defensas urbanas, por aquel entonces construidas solo en parte.

FUENTE: ATLAS BLAEU-VAN DER HEM

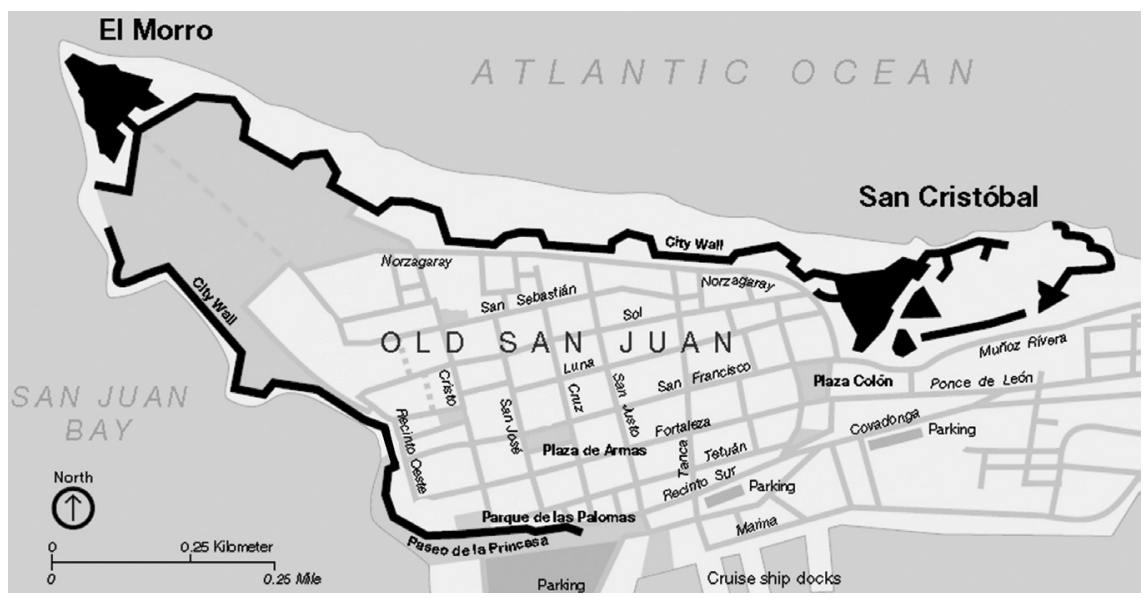

FIgURA 4B | Mapa actual del Viejo San Juan. Las líneas y sombras negras perimetrales corresponden a las murallas y fortalezas existentes. Se aprecia que las murallas hacia su lado este fueron completamente derribadas, y solo parcialmente hacia el sur.

FUENTE: FOTO CORTESÍA DE IMAGENESMY.COM, BAJADA EN OCTUBRE DE 2017 
Las crónicas históricas muestran, pues, una situación completamente diferente en San Juan y Cartagena, si las comparamos. En Puerto Rico, la sociedad en su conjunto estuvo a favor del derribo, después de haber luchado por él durante décadas. En Cartagena, tal como hemos visto, la cuestión estuvo lejos de la unanimidad.

\section{¿Expansión urbana o salud pública? \\ Los casos de varias ciudades latinoamericanas}

Si miramos otras ciudades latinoamericanas y caribeñas, el largo "período dubitativo" cartagenero no se halla en ninguna otra parte. Por ejemplo, la ciudad mexicana de Veracruz derribó el lado tierra de sus murallas en unos pocos meses en 1880 (figura 5), con la banda municipal tocando para acompañar a los obreros en su primer día de trabajo, tal y como dicen las crónicas, en un entusiasmo similar al descrito más arriba para San Juan. La sensación de libertad y la alegría que acompañaron dichos trabajos, llevados a cabo en su mayor parte por entusiastas residentes, son claro signo de una conexión entre murallas y ocupación española. La inevitable conclusión es que, para muchos latinoamericanos de la época, si se derribaba el símbolo colonial por excelencia, el poder colonial sería repelido (caso de Puerto Rico, bajo dominio español hasta 1898) o bien su memoria sería borrada (caso de Cartagena de Indias, independiente desde 1819). En consecuencia, una primera explicación del derribo de las murallas es netamente nacionalista: las nuevas repúblicas americanas borran de sus paisajes urbanos cualquier huella visual dejada por la antigua potencia colonial. Los procesos simbólicos desempeñan, pues, un papel principal, reclamando reformas urbanas y la demolición.

Las murallas urbanas han sido siempre estructuras segregadoras, tanto en época medieval como más recientemente. Así, Creighton (2007) afirma que no pocas murallas "have violent histories and have changed political or national allegiance in the past. Moreover, city walls, while outwardly embracing populations, also inevitably serve to exclude or marginalize other social groups" (p. 345). Este autor reporta procesos de contestación en la ciudad de Sana'a, Yemen, en años recientes, un hecho que demuestra claramente que las murallas urbanas son estructuras que suscitan, aun hoy en día, opiniones encontradas. Bruce y Creighton (2006) usan ciudades amuralladas europeas como trabajo de campo para demostrar su afirmación de que el patrimonio es "disonante" por definición, cuando escriben que "town walls can be conceptualised as a 'dissonant' form of heritage whose value is contested between different interest groups and whose meanings are not static but can be rewritten" (p. 234).

En conclusión, no solo en América Latina las murallas son estructuras polémicas, sino que se encuentran las mismas actitudes hacia ellas en otras latitudes, como en Europa y Asia, según recientes investigaciones. 


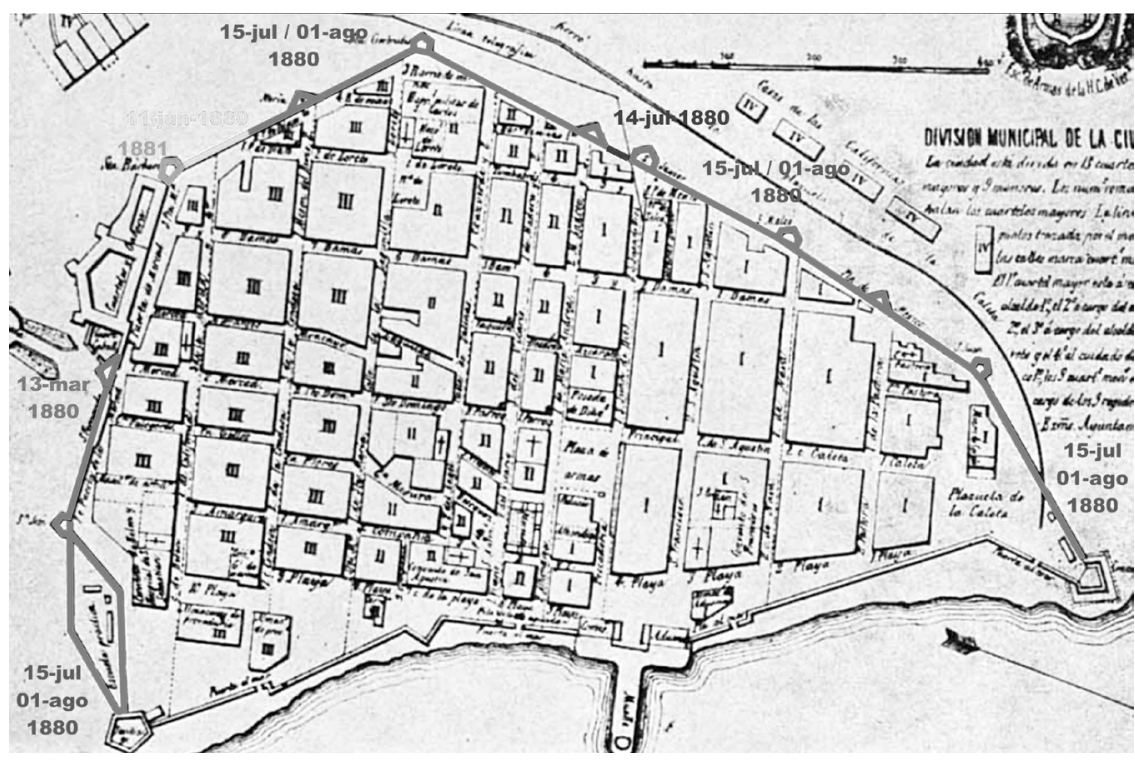

Figura 5 | Esquema de demolición del lado tierra de las murallas de Veracruz, México, que tuvo lugar en tan solo unos meses (marzo a agosto de 1880). Nótese que se priorizó el derribo de la muralla de tierra antes que la de mar, para conectar el centro histórico con los nuevos barrios surgidos fuera de él.

FUENTE: FOTO CORTESÍA DE BLOG "VERACRUZ ANTIGUO", HTTPS://AGUAPASADA.WORDPRESS.COM /20I 5/O5/24/I 880-DEMOLICION-DE-LA-MURALLA-DE-TIERRA-EN-VERACRUZ/, BAJADA EN SEP TIEMBRE DE 2017

Otro argumento que parece importante en este contexto es el de la 'expansión'. Un ejemplo de ello es la ciudad de Lima, Perú, que demolió sus murallas en dos años, empezando en 1868 (Palmeiro, Lombardi \& Montuori, 2012), ya que, según afirma Heineberg (1996), se habían convertido en un obstáculo al progreso de la ciudad. Este mismo autor escribe, para el caso de Montevideo, Uruguay, que en 1829 el primer gobierno nacional independiente ordenó la destrucción inmediata de las fortificaciones de la capital, ya que eran un impedimento a la expansión de la ciudad, una tarea que duró varios años. En suma, hay evidencias de que muchos centros históricos latinoamericanos se quedaron sin sus cordones amurallados por causa de la expansión urbana como motivo primario. En San Juan, como se dijo más arriba, esta demolición fue básicamente en la zona de la Puerta de Tierra, justamente el área que conecta la ciudad antigua con los nuevos barrios, siendo esto una prueba más de que la expansión y la conexión entre los barrios antiguos y los nuevos fue la principal razón tras las demoliciones. Todos estos derribamientos fueron saludados jubilosamente por el conjunto de las poblaciones residentes: el 'progreso' fue el impulsor de acciones; en cambio, la conservación del patrimonio no tenía ningún papel en el discurso público de la época. 
Uno de los argumentos que más se repitió entre 1880 y 1920 en América Latina fue que las murallas debían ser derribadas por razones de salud pública. Este argumento surgió inicialmente en Europa y después se propagó por el continente latinoamericano: Almandoz (2000) reporta los detalles de este debate según se dio en la ciudad de Caracas y Agostoni (2003) investigó el tema en la Ciudad de México. En Cartagena, a pesar de que, según las crónicas, en efecto la higiene alrededor de las murallas era muy deplorable, algunos autores han visto en todo este discurso un modo de aislar y estigmatizar a las clases más bajas por parte de las elites urbanas, que así mantendrían a esas capas más pobres de la población por fuera del progreso emergente de aquella época (Deavila Pertuz, 2010). Un reciente trabajo de Valdemar Villegas (2017) profundiza en aspectos técnicos e impactos sociales de esta 'higienización' en Cartagena, cuyo objetivo final fue no solo la limpieza del ambiente, sino la 'limpieza social' en su sentido más amplio. Ante las medidas que se tomaron en la ciudad en pro de esta higiene, afirma este autor que

si bien fue visible la adquisición de cierto equipamiento urbano, las necesidades de los sectores pobres no fueron atendidas, más bien hubo negligencia y abandono. Es más, los barrios denominados como 'pobres' fueron estigmatizados como espacios antihigiénicos e inmorales que había que sanear en aras de la modernización (p. 186).

Décadas después, argumentos similares se usarían contra diversos barrios de invasión asentados al lado de las murallas, con lo cual se constata la permanencia de una dialéctica perversa contra la población más vulnerable de la ciudad (Deavila Pertuz \& Román Romero, 2008). Así, nos hallamos ante unas capas pobres de población frente a una modernidad discriminadora, de la que dice Valdemar Villegas (2017): "La pretendida modernidad, a imagen y semejanza de las urbes del viejo continente, se redujo a la imaginación de una elite que saciaba su intentada emulación en retóricos discursos de salón” (p. 184). Guerrero Palencia (2014) constata la incapacidad de la elite blanca y andina en cuanto a crear buenas condiciones sociales para todos los habitantes de la ciudad, señalando además un interesante matiz político: "En este sentido los discursos eugenésicos expresados en lo racial y lo higiénico, se convirtieron en justificaciones que facilitaron el desarrollo de una hegemonía centralista andina, en la que las zonas costeras seguían siendo consideradas espacios marginalizados, a los que había que llevar el ideal de progreso y la civilización" (p. 118).

En el caso de San Juan, Dilla Alfonso (2014, p. 83 y ss.) reporta que la situación de sobrepoblación en la ciudad era tan grave que los problemas de higiene eran mucho más reales, aunque a la hora de hallar nuevos espacios y embellecer la ciudad, el desplazamiento de los habitantes de raza negra y de las capas más pobres fue un hecho.

Como se ve, esta discusión se dio, con diferentes matices, en todo el continente, ya que, en no pocas ciudades, las elites más progresistas justificaron la demolición con una mejor salubridad a causa -según se decía- de una mejora en la aireación de la ciudad.

Vale la pena, pues, detenerse en este argumento de la circulación del aire. De hecho, vemos que en Cartagena este argumento no se sostiene, ya que las demoliciones de las murallas comprendieron sobre todo las secciones del este y del sur del 
cordón. Y el hecho es que las brisas sobre la ciudad soplan mayormente desde el norte (Centro de Investigaciones Oceanográficas e Hidrográficas del Caribe [ $\mathrm{CIOH}$ Caribe], 2010). Si la demolición parcial hubiera sido motivada por cuestiones de salubridad, la parte de murallas que se habría derribado hubiera sido el sector norte, para favorecer la entrada de aire. Así, la explicación de higiene pública no puede ser considerada en este contexto. En cambio, si se mira la demolición parcial desde el punto de vista de una mejora de la conexión del centro histórico con el resto de la ciudad, que se iba expandiendo hacia el este, entonces todo cobra sentido. De hecho, la demolición del segmento de muralla en lo que es hoy día la avenida Venezuela tuvo como propósito principal conectar el centro histórico con La Matuna, un nuevo barrio de servicios construido sobre un caño desecado en las primeras décadas del siglo xx (figura 3B) y a partir de ahí con el resto de la ciudad. En este aspecto, pues, Cartagena sigue los patrones y tendencias de otras ciudades latinoamericanas en las que la expansión urbana fue determinante para derribar sus murallas, con el argumento de la higiene como mera excusa.

La cuestión de la 'conexión' o 'expansión' cobra todavía más importancia en el contexto general de crecimiento urbano de las ciudades de América Latina: estas muestran claros procesos de suburbanización ya desde mediados del siglo xIX y las murallas urbanas se vuelven así un obstáculo evidente entre la 'ciudad antigua' y la 'ciudad nueva'. En los casos de Cartagena y San Juan, este proceso expansivo extramuros es comparativamente muy tardío. En San Juan, los militares españoles impidieron cualquier expansión fuera del recinto amurallado, de modo que solo en la década de 1890 se empezó tímidamente a construir por fuera, en la zona de Puerta de Tierra. En la década de 1900 y siguientes, con la isla formando parte de la Unión Americana, se iniciaría un vasto proceso de suburbanización parecido a los que se dieron en las ciudades estadounidenses. En Cartagena, los nuevos barrios extramuros de El Cabrero y Manga empezaron a construirse en las décadas de 1890 y 1900, respectivamente. Aquí emerge una hipótesis sobre la relación entre el mantenimiento de las murallas y una expansión suburbana tardía, ya que otras ciudades que habían demolido sus murallas anteriormente iniciaron estos procesos expansivos mucho antes que Cartagena y San Juan y de modo más intensivo.

En Cartagena, el argumento de la higiene pública fue usado repetidamente por las autoridades para justificar la demolición. Así, un correo del Ministerio de Obras Públicas de 1916 escribe excusándose ante los cartageneros y usando ampliamente el argumento de la salubridad para justificar la demolición de un segmento de muralla, una misiva que revela que la tensión entre conservar las murallas y derribarlas estaba irresuelta (Meisel Roca, 2009):

Tenemos que pedir excusas, muy especialmente a los cartageneros por habernos permitido tocar a las antiguas murallas construidas por los españoles; comprendemos perfectamente el interés histórico que tienen, y sólo por considerar este sacrificio necesario y muy provechoso para la salubridad pública hemos podido resolvernos a recomendar su demolición parcial. (p. 140) 
Este texto es particularmente interesante ya que, por primera vez, aparece el término "interés histórico" en un documento escrito por una autoridad colombiana sobre Cartagena.

Meisel Roca (2009) argumenta -sin ponderarlas- que hubo tres razones por las que las murallas de Cartagena eran vistas como un obstáculo: la primera era económica, ya que las murallas constituían una barrera física hacia la ciudad nueva; la segunda era de índole social, y era la baja apreciación del patrimonio urbano construido en la era 'preturística' de la ciudad; finalmente, la tercera razón tenía que ver con la salud pública, como se ha discutido más arriba.

La presente sección concluye, pues, enfatizando que el argumento de la salubridad no fue más que un falso argumento, ya que, habiendo visto los patrones de derribo de varias ciudades latinoamericanas, queda claro que el motivo principal fue la conexión entre el centro histórico y la nueva ciudad que emergía fuera de las murallas, de modo que ambas partes pudieran articularse en un solo espacio. Esta configuración preservaría el simbolismo del centro histórico, así como su función de centro administrativo y de poder, mientras que la función residencial (para clases altas) y parcialmente la industrial serían expulsadas a zonas periféricas, lejos del centro. De este modo, se introdujo un dualismo en las antiguas ciudades coloniales hispanas que ha prevalecido en muchas de ellas hasta nuestros días. Finalmente, el argumento 'nacionalista' puede ser visto como trasfondo de algunas discusiones de la época.

\section{Las 'excepciones': cómo Cartagena y San Juan preservaron sus murallas. Implicaciones urbanísticas}

Con el trasfondo de los poderosos argumentos de la 'higiene pública' y la 'expansión urbana' empujando la demolición de numerosas fortificaciones urbanas, la presente sección trata de ofrecer explicaciones sobre las 'anomalías urbanas' que significaron el mantenimiento de las murallas en Cartagena y San Juan, explicaciones que a la postre son tan simples como contundentes.

En el caso cartagenero, el antagonismo entre las elites mencionado en la segunda sección se saldó con la victoria de las más conservadoras. Fueron estos sectores los que, a pesar de ser minoritarios, vencieron en la batalla. Pero también existió un motivo mucho más prosaico que salvó las murallas: pese a que el gobierno nacional emitió un decreto para derribarlas, el gobierno local estaba tan corto de fondos que no tuvo modo de pagar la demolición (Samudio Trallero, 2006, p. 4).

Scarpaci (2005) ilustra cómo finalmente, y tras décadas de discusiones, se resolvió la cuestión de modo definitivo: en 1923, el alcalde de la ciudad invitó a un grupo de respetables ciudadanos, miembros de la elite local, a formar la Sociedad de Mejoras Públicas de Cartagena (es decir, la comisión local de monumentos), cuya misión sería el mantenimiento y embellecimiento de los espacios públicos y monumentos, en especial la arquitectura militar. Creada por una normativa local en 1923, aprobada un año más tarde por el Congreso del país, y a semejanza de otras Sociedades de Mejoras Públicas que se establecieron en las principales ciudades de Colombia, empezó a operar en el año 1924. Esta entidad pertenecía a las elites locales, a las cuales el sector público entregaba de este modo la mejora del espacio urbano y de 
sus monumentos. El mismo Scarpaci afirma que de este modo tuvo lugar la solución más radical que se adoptó en el continente en lo que a conservación de espacios públicos se refiere, en el sentido de que se dejó por completo esta tarea en manos privadas (cf. también Cunín \& Rinaudo, 2006).

Escribiendo sobre esta cuestión de la década de 1920, Deavila Pertuz (2010) sostiene que, con la creación de la Sociedad de Mejoras Públicas, "se imprime un nuevo paradigma en la ciudad; el legado arquitectónico de la colonia, antes condenado a la desaparición, adquiere valor dentro de un prematuro proceso de constitución de una ciudad turística” (p. 2). Es, por tanto, a la vista de futuros desarrollos turísticos (que aún tardarían décadas en llegar) que algunos integrantes de la elite urbana consiguen que se conserven para siempre las murallas, una tarea que acometerán ellos mismos desde la recién creada Sociedad.

En lo que se refiere a San Juan, quedó como una plaza altamente estratégica, donde los militares españoles impidieron cualquier cambio en las estructuras fortificadas hasta 1897, cuando se dio una demolición parcial, como se explica más arriba. Un año más tarde, las murallas se usaron para proteger la ciudad frente a las fuerzas invasoras estadounidenses. A partir de la década de 1900, Puerto Rico se convirtió en el bastión estadounidense del Caribe, protegiendo la construcción del Canal de Panamá y más tarde su operación. De hecho, solo a partir de 1912 el gobierno federal estadounidense empezó a compartir el manejo de las estructuras militares coloniales con el gobierno de la isla, básicamente para que este contribuyera a los costos de mantenimiento de aquellas. Así las cosas, amplias secciones de las murallas y los fortines continuaron siendo usados como instalaciones militares por los norteamericanos, sobre todo como almacenes. El uso militar del sistema de fortalezas colonial siguió hasta la Segunda Guerra Mundial, ya que el gobierno federal americano desplegó en ellas artillería moderna de forma preventiva (Gutiérrez, 2005, p. 64). Los militares conservaron su autoridad sobre buena parte de las murallas y fortines hasta que, en 1961, decidieron transferirlos al National Parks Service estadounidense. Con ello, estamos ante un período inusualmente largo de uso militar de fortalezas coloniales, que es único en toda Latinoamérica y que explica tanto la conservación de las murallas como su rápida transición a atractivo turístico (Álvarez Curbelo, 2009; Flores 2009; González Vales, 2009; Santiago Cazull, 2006).

Alguien puede argumentar que, en ambas ciudades, con las demoliciones parciales que garantizaban la conexión entre la ciudad antigua y la nueva, la demolición completa de las murallas no fue necesaria. Por tanto, la muralla lado mar pudo seguir en pie al no ser un estorbo para la citada conexión. Nosotros no creemos que esta explicación sea correcta, ya que también debería dar cuenta de por qué fueron derribadas las murallas del lado mar de otras ciudades coloniales hispanas (La Habana, Veracruz, etcétera). 


\section{Conclusiones}

El presente artículo ha repasado y ponderado las diferentes causas que explican los procesos de demolición de murallas en América Latina, así como los casos únicos de Cartagena de Indias y San Juan de Puerto Rico, que consiguieron conservar sus estructuras amuralladas. Se ha determinado que, bajo un trasfondo nacionalista, la expansión urbana y la conexión de barrios fueron las causas de demolición de murallas, mientras que los argumentos de higiene pública fueron usados como meros pretextos. Las causas para mantener las murallas difieren en ambas ciudades: en el caso cartagenero, remiten a una apuesta temprana por el turismo y, junto con ello, a la falta de presupuesto para la demolición; en el caso sanjuanero, fue su uso continuado y extraordinariamente largo como instalaciones militares.

Es de resaltar que, con la excepción de la conservación de sus murallas, los centros históricos de Cartagena y San Juan compartirían idéntico destino con el resto de centros históricos coloniales latinoamericanos en lo que se refiere a sus desarrollos durante el siglo xx. En efecto, todos ellos verían primero un proceso de decadencia largo y profundo para después ser regenerados en lo que Scarpaci (2005) considera las dos caras de una misma moneda de la estrategia capitalista de valoración de centros históricos. En conclusión, exceptuando sus 'anómalas' murallas y dentro de sus respectivos contextos nacionales de planeación urbana, Cartagena y San Juan experimentaron los mismos procesos y las transformaciones comunes a todas las urbes del continente desde mediados del siglo xIx hasta las primeras décadas del xx. Así, el hecho de conservar las murallas no significó nada especial para estas dos ciudades en lo que se refiere a desarrollo urbano.

Cabe subrayar aquí cómo, con posterioridad a la época analizada, en el transcurso del siglo xx ambas ciudades experimentarían procesos de suburbanización (que en San Juan serían de proporciones gigantescas, debido a que se trasplantaron a la isla las normas de planeación estadounidenses), así como procesos de turistificación, lo que las ha llevado a ser dos destinos caribeños altamente cotizados, tanto por sus playas como por su patrimonio militar construido. Los nuevos barrios fueron construidos para las clases más pudientes en estilo art déco en Cartagena y en estilo city beautiful en San Juan, pero también con presencia de barrios de construcción informal ocupados por las clases bajas, de modo similar a lo acontecido en otras ciudades latinoamericanas. Estas cuestiones quedan, sin embargo, fuera de nuestro trabajo y se constituyen en interesantes futuras investigaciones que podrán completar lo reportado en el presente artículo.

Al final, las circunstancias más bien fortuitas que llevaron a la conservación de las murallas en ambas urbes (Segovia Salas, 1987, escribió que haber conservado las murallas de Cartagena fue un "milagro"), acabaron siendo altamente beneficiosas con el correr del tiempo: las murallas son hoy en día importantes monumentos de carácter icónico que inspiran orgullo y sentido de pertenencia a los residentes. Asimismo, distinguen estéticamente a estas ciudades, ya que son estructuras únicas en América Latina y constituyen, por tanto, una fuente de competitividad, algo esencial para ambas, ya que son hoy en día importantes destinos turísticos de talla internacional. 


\section{Agradecimientos}

Los autores agradecen a Simon Curtis ( $\dagger$ ) y Andrew Smith (ambos de la University of Westminster, Londres) sus lecturas y comentarios a las primeras versiones de este artículo. Asimismo, se reconocen las aclaraciones y comentarios de Haroldo Dilla (Universidad Arturo Prat, Chile) y los comentarios y ánimos dados por Nadia Fava (Universitat de Girona, Cataluña). Se agradece también a la Puerto Rico Drawing Historic Society y a la Sociedad Puertorriqueña de Planificación las informaciones suministradas y la corroboración de datos históricos y de planeación para San Juan. Finalmente, damos las gracias al arquitecto Alberto Samudio Trallero por sus aportaciones en lo que se refiere a Cartagena.

\section{Referencias bibliográficas}

Agostoni, C. (2003). Monuments of progress. Modenization and public health in Mexico City, 1867-1910. Calgary, Boulder / Ciudad de México: University of Calgary Press, University Press of Colorado / Universidad Nacional Autónoma de México.

Almandoz, A. (2000). The shaping of Venezuelan urbanism in the hygiene debate of Caracas, 1880-1910. Urban Studies, 37(11), 2.073-2.089. https://doi. org $/ 10.1080 \% 2 \mathrm{~F} 713707233$

Almandoz, A. (2002). Urbanization and urbanism in Latin America: from Haussmann to ciam. En A. Almandoz (ed.), Planning Latin America's Capital Cities 1850-1950. Londres / Nueva York: Routledge.

Almandoz, A. (2010). From urban to regional planning in Latin America. Planning Perspectives, 25(1), 87-95. https://doi.org/10.1080/02665430903515840

Álvarez Curbelo, S. (2009). De "zona polémica" a barrio: Puerta de Tierra y el nacimiento de un espacio urbano en San Juan. En L. E. González Vale, M. Flores, A. Sepúlveda Rivera, S. Alvarez Curbelo \& A. Bird Carmona (eds.), San Juan: La ciudad que rebasó sus murallas. San Juan: Fundación Puertorriqueña de las Humanidades.

Ávila Domínguez, F. (2008). La representación de Cartagena de Indias en el discurso turístico. Cuaderno de Trabajo n. ${ }^{\circ}$ 2. México: Proyecto Afrodesc. http://www. nacionmulticultural.unam. $\mathrm{mx} / \mathrm{mezinal} /$ docs/6185.pdf

Bernal, C. (2010). Metodología de la Investigación para administración, economía, humanidades $y$ ciencias sociales (3. ${ }^{\mathrm{a}}$ ed.). Bogotá: Pearson.

Bruce, D. \& Creighton, O. (2006). Contested identities: the dissonant heritage of European town walls and walled towns. International Journal of Heritage Studies, 12(3), 234-254. https://doi.org/10.1080/13527250600604498

Carrillo Romero, H., Cabarcas Cañate, G., Vargas Hernández, A. \& Puello Pájaro, Y. (2013). El desarrollo de la actividad turística en Cartagena de Indias: implicaciones sociales y urbanas: 1943-1978. PalObra, (13), 190-210. https://dialnet.unirioja.es/servlet/ articulo?codigo $=5077595$

Centro de Investigaciones Oceanográficas e Hidrográficas del Caribe (сіон Caribe). (2010). Climatología de los principales puertos del Caribe colombiano, Cartagena de Indias. Reporte en línea. 
Cortés, C. \& Iglesias, L. (2004). Generalidades sobre metodología de la investigación. Colección Material Didáctico 10. Ciudad del Carmen, Campeche, México: Universidad Autónoma del Carmen. En http://www.unacar.mx/contenido/gaceta/ediciones/ metodologia_investigacion.pdf

Creighton, O. (2007). Contested townscapes: the walled city as a world heritage. Word Archaeology, 39(3), 339-354. https://doi.org/10.1080/00438240701464822

Cunín, E. \& Rinaudo, C. (2006). Las murallas de Cartagena entre patrimonio, turismo y desarrollo urbano. El papel de la Sociedad de Mejoras Públicas. MEMORIAS, Revista digital de Historia y Arqueología desde el Caribe colombiano, 2(2). https://dialnet. unirioja.es/servlet/articulo?codigo $=1185383$

Deavila Pertuz, O. C. (2010). Políticas urbanas, pobreza y exclusión social en Cartagena: durante la segunda mitad del siglo xx. Manuscrito inédito, Universidad de Cartagena, Cartagena de Indias.

Deavila Pertuz, O. C. \& Román Romero, R. (2008). Políticas urbanas, pobreza y exclusión social en Cartagena: el caso Chambacú 1956-1971. Tesis de grado, Universidad de Cartagena, Cartagena de Indias.

Delgado Mercado, O. (2010). Preservación de monumentos y responsabilidad pública. Patrimonio. Revista Oficial de la Oficina Estatal de Conservación Histórica de Puerto Rico, 1, 62-71.

Dilla Alfonso, H. (2014). Ciudades en el Caribe: un estudio comparado de Santo Domingo, San Juan, La Habana, Miami. México, D.F.: Facultad Latinoamericana de Ciencias Sociales (Flacso) / Buenos Aires: Café de las Ciudades.

Flores, M. (2009). El estado de las defensas de San Juan y el derribo de sus murallas. En L. E. González Vale, M. Flores, A. Sepúlveda Rivera, S., Álvarez Curbelo \& A. Bird Carmona (eds.), San Juan: La ciudad que rebasó sus murallas. San Juan: Fundación Puertorriqueña de las Humanidades.

Giaimo, S. (2002). Cartagena de Indias, sobrellevando la crisis. Taller "Cómo es Cartagena al finalizar el siglo xx". Informe inédito.

González Vale, L. E. (2009). El derribo de las murallas y el ensanche de San Juan: Apuntes sobre un expediente. En L. E. González Vale, M. Flores, A. Sepúlveda Rivera, S. Álvarez Curbelo \& A. Bird Carmona (eds.), San Juan: La ciudad que rebasó sus murallas. San Juan: Fundación Puertorriqueña de las Humanidades.

Guerrero Palencia, L. (2014). Eugenesia y biopolitica: la modernización de la ciudad-puerto de Cartagena 1910-1930. Tesis de maestría. Quito: Flacso-Sede Ecuador. http://hdl. handle.net/10469/6668

Gutiérrez, R. (2005). Fortificaciones en Iberoamérica. Madrid: Fundación Iberdrola y Ediciones El Viso.

Hardoy, J. E. (1978). La construcción de las ciudades de América Latina a través del tiempo. Problemas del Desarrollo, 9(34), 83-118. http://dx.doi.org/10.22201/ iiec.20078951e.1978.34.40920

Hardoy, J. E. (1992). Theory and practice of urban planning in Europe, 1850-1930: its transfer to Latin America. En J. E. Hardoy \& R. M. Morse (eds.), Rethinking the Latin American City (pp. 20- 49). Washington, D.c.: Woodrow Wilson Center Press / The Johns Hopkins University Press. 
Hamel, J., Dufour, S. \& Fortin, D. (1993). Case Study Methods. Newbury Park, CA: Sage Publications.

Heineberg, H. (1996) Desarrollo y estructura de antiguas ciudades coloniales españolas en América del Sur según los planos de Lima (1872), Bogotá (1852) y Montevideo (1865). En Banco de la República (ed.), Tras las huellas: dos viajeros alemanes en tierras latinoamericanas. Bogotá: Banco de la República.

Hernández, S., Fernández, C. \& Baptista, L. (2010). Metodología de la investigación (5a. ed.). México D.F.: Mc Graw Hill.

Meisel Roca, A. (2009). ¿Por qué perdió la Costa Caribe el siglo XX? Cartagena: Ediciones del Banco de la República. http://www.banrep.gov.co/sites/default/files/publicaciones/ archivos/lbr_meisel_ensayos.pdf

Mignucci, A. (2012). Modern Urbanism in Puerto Rico 1928-1974; from abstract doctrines to concrete landscapes. Publicación en línea. Descargada en abril de 2017 de: https:// www.academia.edu/12425420/Modern_Urbanism_in_Puerto_Rico_from_abstract_ doctrines_to_concrete_landscapes_2012_

Montoya Garay, J. W. (2013). Planificación, urbanismo y la construcción de la Bogotá moderna. De Brunner a Le Corbusier. En I. Duque (ed.), Historiografía y planificación urbana en América Latina (pp. 73-168). Bogotá: Universidad Nacional de Colombia.

Oxman, A. \& Guyatt, G. (1993). Guía para la lectura de Artículos de Revisión. Boletín de la Oficina Sanitaria Panamericana, 114(5), 446-458. http://iris.paho.org/xmlui/ handle/123456789/16258

Pabon-Chameco, A. (2016). San Juan de Puerto Rico... Utopía de tres imperios. XIV Coloquio Internacional de Geocritica, Universitat de Barcelona, Barcelona. http://www.ub.edu/ geocrit/xiv-coloquio/ArleenPabon.pdf

Palmeiro, G., Lombardi, A. \& Montuori, P. (2012). Lima. The historic city centre. Analysis and restoration. Roma: Gangemi Editore.

Programa de Naciones Unidas para el Desarrollo (PNUD) / Unesco (1989). Seminario/Debate sobre la conservación del centro histórico de Cartagena. Informe inédito.

Samudio Trallero, A. (2006). Cartagena veintiún años después de ser declarada patrimonio mundial. "MEMORIAS". Revista digital de Historia y Arqueología desde el Caribe colombiano, 3(6). https://dialnet.unirioja.es/servlet/articulo?codigo=2209728

Santiago Cazull, H. F. (2006). Morfología y estratos de significación en los recintos sur y suroeste de las murallas de Fortificación de San Juan, Puerto Rico. En N. Sanz (ed.), American fortifications and the World Heritage Convention. París: Unesco / World Heritage Centre.

Scarpaci, J. (2005). Plazas and barrios. Heritage, tourism and globalization in the Latin American Centro Histórico. Tucson, Az: The University of Arizona Press.

Segovia Salas, R. (1987). Las fortificaciones de Cartagena de Indias: estrategia e historia. Bogotá: Carlos Valencia Editores.

Sepúlveda Rivera, A. (2000). El centro histórico de San Juan de Puerto Rico. Tiempos de América, (5-6), 65-76. http://dx.doi.org/10.6035/Tiempos

Stake, R. E. (1995). The art of case study research: Perspective in practice. Londres: Sage Publications.

Valdemar Villegas, F. F. (2017). Modernización urbana y exclusión social en Cartagena de Indias, una mirada desde la prensa local. Territorios (36), 159-188. http://dx.doi. org/10.12804/revistas.urosario.edu.co/territorios/a.5157 